\title{
Benign epithelial oral lesions - association with human papillomavirus
}

\author{
Alicia-Rumayor Piña ${ }^{1}$, Felipe-Paiva Fonseca ${ }^{1,2}$, Flávia-Sirotheau-Corrêa Pontes ${ }^{3}$, Hélder-Antônio-Rebelo \\ Pontes $^{3}$, Fábio-Ramôa Pires ${ }^{4}$, Adalberto Mosqueda-Taylor ${ }^{5}$, José-Manuel Aguirre-Urizar ${ }^{6}$, Oslei-Paes de \\ Almeida ${ }^{1}$
}

${ }^{1}$ Oral Pathology Section, Department of Oral Diagnosis, Piracicaba Dental School, University of Campinas. Brazil

${ }^{2}$ Department of Oral Surgery and Pathology, School of Dentistry, Universidade Federal de Minas Gerais. Brazil

${ }^{3}$ Service of Oral Pathology, João de Barros Barreto University Hospital, Federal University of Pará. Brazil

${ }^{4}$ Oral Pathology, Department of Surgery and Diagnosis, Dental School, State University of Rio de Janeiro. Brazil

${ }^{5}$ Departamento de Atención a la Salud, Universidad Autónoma Metropolitana Xochimilco, México

${ }^{6}$ Departamento de Estomatología II. Facultad de Medicina y Enfermería. Universidad del País Vasco/EHU. España

Correspondence:

Oral Pathology, Piracicaba Dental School

University of Campinas (UNICAMP)

Av. Limeira 901, P.O. Box 52, 13414-903

Piracicaba, São Paulo, Brazil

ali84rum@hotmail.com

Received: $12 / 10 / 2018$

Accepted: $13 / 03 / 2019$
Piña AR, Fonseca FP, Pontes FSC, Pontes HAR, Pires FR, Mosqueda-Taylor A, Aguirre-Urizar JM, de Almeida OP. Benign epithelial oral lesions - association with human papillomavirus. Med Oral Patol Oral Cir Bucal. 2019 May 1;24 (3):e290-5.

http://www.medicinaoral.com/medoralfree01/v24i3/medoralv24i3p290.pdf

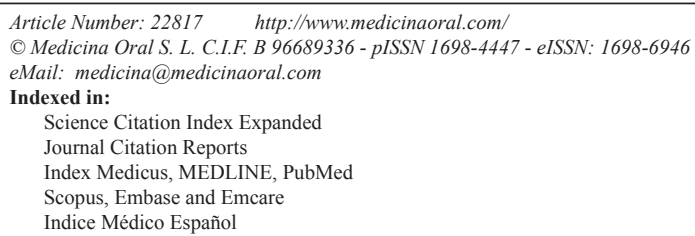

\begin{abstract}
Background: The presence of human papilloma virus in benign oral lesions has been studied by different techniques obtaining extremely variable results. The objective of this study was to determine the presence of human papillomavirus in 83 cases of benign hyperplastic epithelial oral lesions.

Material and Methods: Eighty-three oral lesions with clinical or histopathological features suggestive of HPV infection were retrieved from the files of four oral pathology services. Demographic data were obtained from patient's medical charts. All cases had available clinical image, H\&E preparations and paraffin blocks with enough tissue for HPV detection by in situ hybridization, and immunohistochemical reactions for Ki67.

Results: Episomal positivity for wide spectrum HPV was observed in $24 \%$ of the cases; most of them (70\%) HPV $6 / 11$ positive. HPV 16/18 was not detected. Condyloma acuminatum was the most common lesion associated with HPV (75\%), followed by verruca vulgaris (15\%), squamous papilloma and multifocal epithelial hyperplasia, $5 \%$ each. Koilocytes were identified in all the HPV positive cases. Ki67 showed an abnormal proliferation pattern in $90 \%$ of the HPV positive cases; most of them (70\%) showing groups of proliferating cells in focal superficial regions, and in $20 \%$ positivity was seen almost in the whole thickness of the epithelium. HPV negative cases showed Ki67 positive cells restricted to the basal layer.
\end{abstract}


Conclusions: Regarding oral lesions associated with HPV, condyloma is the most common lesion expressing low-risk subtypes. The etiology of squamous papilloma remains controversial as HPV was found in $1.9 \%$ of the cases. The identification of koilocytes and the pattern of expression of Ki67 reflect HPV infection and are helpful for classification. Papillary oral lesions not associated to HPV deserve further studies to better clarify its etiology.

Key words: Human papillomavirus, condyloma, papilloma.

\section{Introduction}

The World Health Organization (WHO) recognizes four human papillomavirus (HPV) related oral lesions; squamous cell papilloma (SP), condyloma acuminatum (CA), verruca vulgaris (VV) and multifocal epithelial hyperplasia (MFEH). These lesions are benign hyperplastic exophytic proliferations of the oral epithelium associated with different subtypes of HPV. Papilloma tend to be solitary and pedunculated, the percentage of HPV positive lesions is highly variable, ranging from $0 \%$ to $100 \%$, with an average of $34 \%$ depending on the detection technique. Low-risk HPV 6 and 11 are the most commonly found subtypes. Histologically SP show sharp-pointed digitiform projections of the epithelium without evident koilocytes or keratohyaline granules. VV is uncommon intraorally, it affects mainly lip vermillion, clinically, a white rough surface is seen, often presenting as multiple or clustered lesions. Features that help distinguishing VV from SP are a thick layer of orthokeratin, prominent keratohyaline granules and presence of koilocytes. VV is associated with HPV 2, 4, 40 and 57. Oral CA corresponds to the counterpart of genital condyloma, usually HPV 6/11 positive, and it can be differentiated from SP by its bulbous, rounded and short projections (1-4). MFEH has well established features and it is associated with HPV 13 and 32, it affects specific groups of individuals in a few regions of the world, particularly Eskimos and Amerindians of North, South and Central America, 5\% of the cases may show papillary/verrucous surface, but not predominantly, as smooth flat papules tend to outnumber the papillary lesions. Prominent acanthosis is a key feature as well as the so called mitosoid figures, which are considered highly characteristic of this condition (5-7). Clinical and histopathological features are supposed to be enough to differentiate these groups of oral epithelial lesions; however, in an oral pathology daily work this differentiation can be difficult, and misuse of terms makes this subject confuse. We herein describe and discuss the association of HPV with 83 benign epithelial hyperplastic oral lesions to better clarify this group of oral mucosal lesions.

\section{Material and Methods}

This was a retrospective study based on eighty-three cases of oral lesions with clinical and/or histopathological features suggestive of HPV association. The cases were retrieved from the files of four oral pathology services. Table 1 summarizes the clinical features of the cases. In addition, for histological comparison, 13 cases of genital condyloma acuminatum from penis (5), anus (5), and vulva (3) previously known to be HPV 6/11 positive were included. All the oral cases had available clinical image, H\&E preparation and paraffin blocks with enough tissue for HPV detection by in situ hybridization (ISH) and for immunohistochemical reactions. The cases were classified according the criteria defined by the WHO, considering squamous papilloma, con-

Table 1. Clinical features.

\begin{tabular}{|c|c|c|}
\hline & n & $\%$ \\
\hline \multicolumn{3}{|l|}{ Gender } \\
\hline Male & 45 & $54.2 \%$ \\
\hline Female & 38 & $45.7 \%$ \\
\hline \multicolumn{3}{|l|}{ Age } \\
\hline $0-10$ & 10 & $12 \%$ \\
\hline $11-20$ & 10 & $12 \%$ \\
\hline $21-30$ & 5 & $6 \%$ \\
\hline $31-40$ & 16 & $19.2 \%$ \\
\hline $41-50$ & 7 & $8.4 \%$ \\
\hline $51-60$ & 17 & $20.4 \%$ \\
\hline $61-70$ & 14 & $16.8 \%$ \\
\hline$\geq 71$ & 4 & $4.8 \%$ \\
\hline \multicolumn{3}{|l|}{ Number of lesions } \\
\hline Solitary & 71 & $85.5 \%$ \\
\hline Multiple & 12 & $14.4 \%$ \\
\hline \multicolumn{3}{|l|}{ Location } \\
\hline Palate & 21 & $25.3 \%$ \\
\hline Tongue & 20 & $24 \%$ \\
\hline Labial mucosa & 16 & $19.2 \%$ \\
\hline Lip vermilion & 13 & $15.6 \%$ \\
\hline Gingiva & 7 & $8.4 \%$ \\
\hline Floor of the mouth & 4 & $4.8 \%$ \\
\hline Buccal mucosa & 2 & $2.4 \%$ \\
\hline \multicolumn{3}{|l|}{ Diagnosis } \\
\hline Squamous papilloma & 52 & $62.6 \%$ \\
\hline Condyloma acuminatum & 16 & $19.2 \%$ \\
\hline Verruca vulgaris & 13 & $15.6 \%$ \\
\hline Multifocal epithelial hyperplasia & 2 & $2.4 \%$ \\
\hline
\end{tabular}


dyloma acuminatum, verruca vulgaris, and multifocal epithelial hyperplasia.

In situ hybridization was performed in $5 \mu \mathrm{m}$ sections using a wide spectrum (WS) probe that includes genotypes $6,11,16,18,31,33,35,39,45,51$ and 52 , and two specific probes; HPV 6/11 and HPV 16/18 (Y1404, Y1411, Y1412, Dako, Carpinteria, CA). The Catalyzed Signal Amplification System (K0620; Dako, Carpinteria, CA) was used for visualization. All procedures were performed following the manufacturer's protocol. Cases of uterine cervix and tongue squamous cell carcinoma were used as positive and negative controls, respectively. The presence of a complete nuclear (episomal) or punctate/dots (integrated) dark brown signals within the epithelial cells were considered positive (8). Immunohistochemistry (IHC) for Ki67 (Dako, MIB-1, 1:100) was also performed in $3 \mu \mathrm{m}$ sections following a known protocol (9).

\section{Results}

There were 45 males and 38 females with a mean age of 41 years (range 2-78 years). Solitary lesions prevailed, and palate, tongue and lip vermilion were the most affected sites. Twenty (24\%) from 83 cases of hyperplastic epithelial oral lesions were positive for the wide spec- trum probe, and 14 (70\%) out of these were of the 6/11 subtype. In all the cases positive cells had an episomal pattern. The high-risk specific probe $16 / 18$ was not positive in any case. Table 2 summarizes the features of the HPV associated oral lesions.

Regarding to diagnosis, cases classified as condyloma were the most associated with HPV, 75\% were positive for the 6/11 specific probe (Fig. 1A-F). Three cases $(23 \%)$ of verruca vulgaris were positive only for the wide spectrum probe, while one case each of SP and MFEH were positive for both probes. Koilocytes were more commonly observed in condylomas and MFEH, followed by VV, most of them in the upper portion of the spinous stratum (Fig. 2).

Ki67 highlighted proliferating cells restricted to the basal layer in $67.4 \%$ of the cases, mainly corresponded to SP. In 27 cases (32.5\%) a more diffuse pattern was observed, in 22 cases besides the basal layer, focal groups of superficial cells expressed Ki67 corresponding to condyloma and $\mathrm{VV}$, while in 5 cases positivity was observed in the whole thickness of the epithelium (Fig. 3). The latter corresponded to CA, 3 of them showing flat acanthosis instead a papillary morphology. From the cases with an abnormal pattern of expression of Ki67, $66.6 \%$ were associated with HPV. Table 3 summarizes

Table 2. Features of the HPV positive cases.

\begin{tabular}{|c|c|c|c|c|c|c|}
\hline Case & Age/ Gender & Site & Diagnosis & Number & $\begin{array}{l}\text { WS } \\
\text { HPV }\end{array}$ & $\begin{array}{l}6 / 11 \\
\text { HPV }\end{array}$ \\
\hline 1 & $56 / \mathrm{M}$ & Tongue & Papilloma & Solitary & + & + \\
\hline 2 & $39 / \mathrm{F}$ & Tongue & Condyloma & Multiple & + & + \\
\hline 3 & $58 / \mathrm{F}$ & Tongue & Condyloma & Multiple & + & + \\
\hline 4 & $55 / \mathrm{F}$ & Lip vermilion & Verruca vulgaris & Solitary & + & Neg \\
\hline 5 & $74 / \mathrm{M}$ & Floor of mouth & Condyloma (flat) & Solitary & + & + \\
\hline 6 & $28 / \mathrm{F}$ & Labial mucosa & Condyloma & Solitary & + & + \\
\hline 7 & 9/M & Lip vermilion & Verruca vulgaris & Solitary & + & Neg \\
\hline 8 & $5 / \mathrm{M}$ & Lip vermilion & Verruca vulgaris & Solitary & + & Neg \\
\hline 9 & $35 / F$ & Labial mucosa & Condyloma (flat) & Solitary & + & + \\
\hline 10 & $60 / \mathrm{M}$ & Labial mucosa & Condyloma & Multiple & + & + \\
\hline 11 & $10 / \mathrm{M}$ & Labial mucosa & Condyloma & Multiple & + & + \\
\hline 12 & $2 / \mathrm{F}$ & Gingiva & Condyloma & Multiple & + & + \\
\hline 13 & $63 / \mathrm{M}$ & Tongue & Condyloma & Multiple & + & + \\
\hline 14 & $35 / \mathrm{M}$ & Tongue & Condyloma & Solitary & + & + \\
\hline 15 & $59 / \mathrm{M}$ & Labial mucosa & Condyloma & Solitary & + & + \\
\hline 16 & $67 / \mathrm{M}$ & Tongue & Condyloma (flat) & Multiple & + & Neg \\
\hline 17 & $11 / \mathrm{M}$ & Labial mucosa & $\begin{array}{c}\text { Multifocal epithelial } \\
\text { hyperplasia }\end{array}$ & Multiple & + & + \\
\hline 18 & $62 / \mathrm{M}$ & Tongue & Condyloma & Solitary & + & + \\
\hline 19 & $38 / \mathrm{M}$ & Labial mucosa & Condyloma & Multiple & + & Neg \\
\hline 20 & $32 / \mathrm{M}$ & Gingiva & Condyloma & Solitary & + & $\mathrm{Neg}$ \\
\hline
\end{tabular}




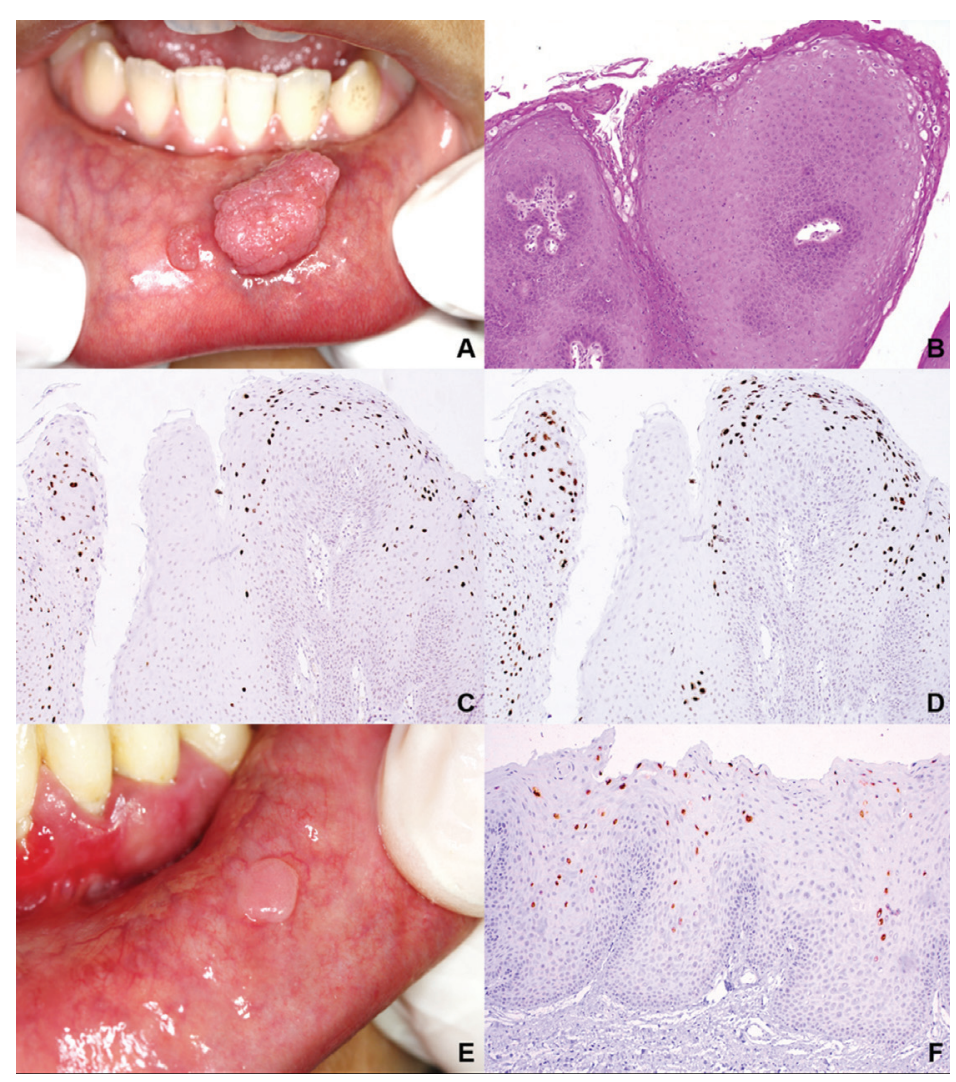

Fig. 1. Condyloma acuminatum (case 11). A. Two nodular lesions with slightly papillary surface. B. Blunt hyperplastic epithelium with papillary rounded projections showing superficial koilocytes (H\&E, 50x) C. Positivity for wide-spectrum HPV (ISH, 100x). D. Positivity for HPV 6/11 (ISH, 100x). E. Flat condyloma (case 9). Solitary smooth surfaced nodule. F. Flat acanthosis with blunt processes showing positivity for HPV 6/11 (ISH, 100x).

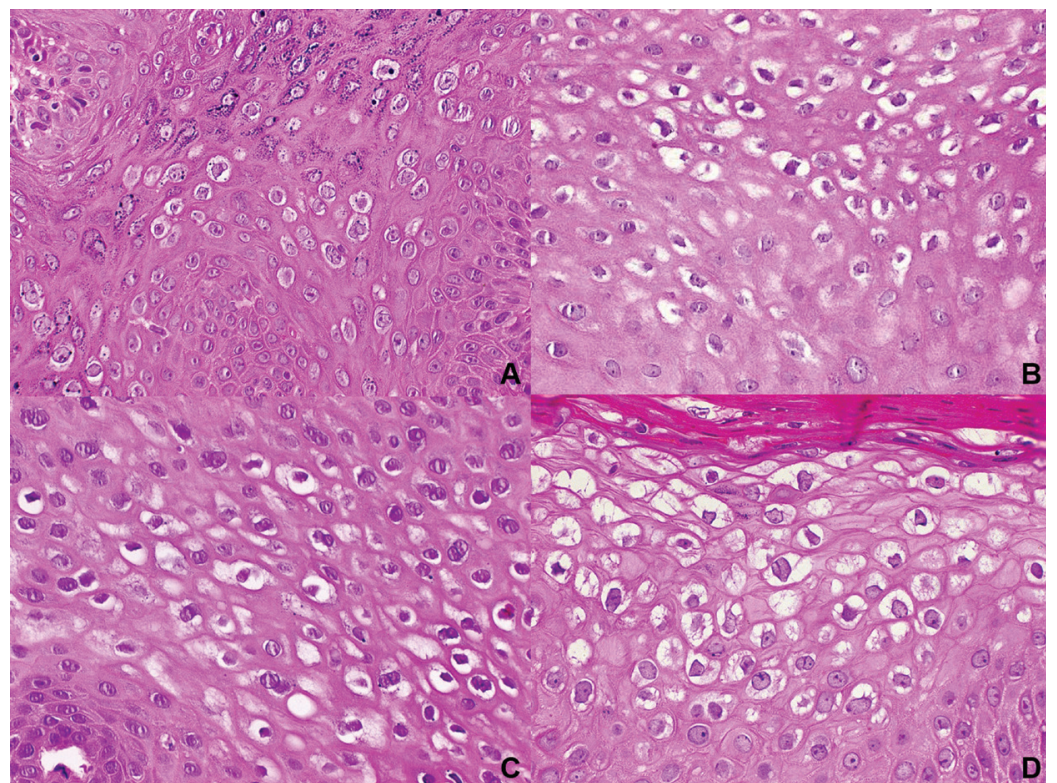

Fig. 2. Koilocytes in oral and genital lesions. A. Labial VV. Coarse keratohyaline granules are evident (H\&E, 400x). B. Condyloma of ventral tongue (Case 13, H\&E, 400x). C. Flat condyloma of floor of the mouth (Case 5, H\&E, 400x). D. Penile condyloma (H\&E, 400x). 


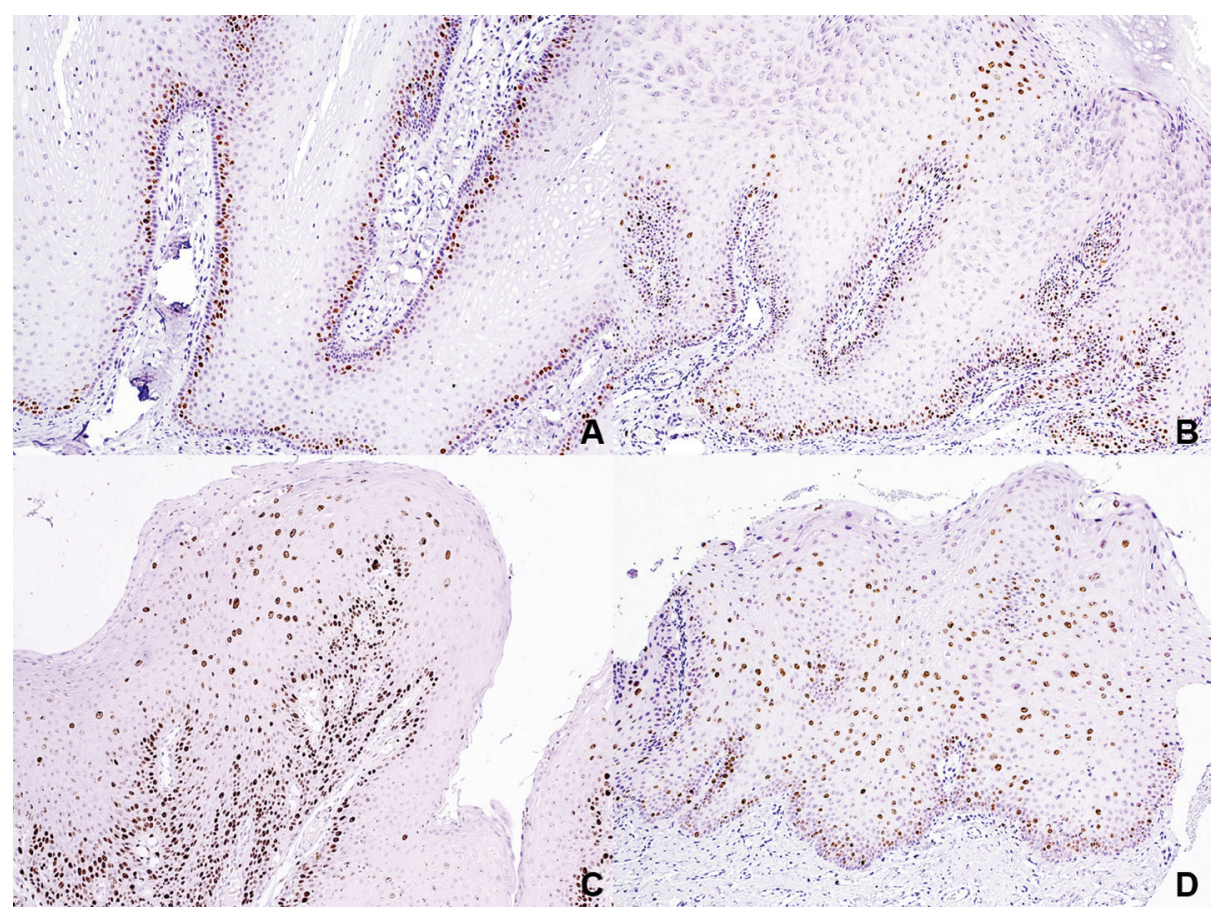

Fig. 3. Immunohistochemical expression patterns of Ki67. A. HPV negative SP showing proliferating cells restricted to the basal layer (IHC, 100x). B. Labial VV showing basal Ki67 and a focal group of cells near the surface (IHC, 100x). C. CA showing proliferating cells in the basal and spinous layer (Case 11, IHC, 100x). D. HPV positive flat condyloma showing acanthosis containing proliferating cells in the whole thickness of the epithelium (case 5) (IHC, 100x).

Table 3. Features according diagnosis.

\begin{tabular}{|l|c|c|c|c|}
\hline Characteristic & $\begin{array}{c}\text { SP } \\
\text { n (\%) }\end{array}$ & $\begin{array}{c}\text { CA } \\
\mathbf{n}(\%)\end{array}$ & $\begin{array}{c}\text { VV } \\
\mathbf{n}(\%)\end{array}$ & $\begin{array}{c}\text { MFEH } \\
\text { n (\%) }\end{array}$ \\
\hline HPV WS & $1(1.9 \%)$ & $15(93.7 \%)$ & $3(23 \%)$ & $1(50 \%)$ \\
\hline HPV 6/11 & $1(1.9 \%)$ & $12(75 \%)$ & $0(0 \%)$ & $1(50 \%)$ \\
\hline Koilocytes & $8(15.3 \%)$ & $15(93.7 \%)$ & $10(76.9 \%)$ & $2(100 \%)$ \\
\hline Ki67 & & & & \\
\hline Basal & $49(94.2 \%)$ & $1(6.2 \%)$ & $4(30.7 \%)$ & $2(100 \%)$ \\
\hline Focal superficial & $3(5.7 \%)$ & $10(62.5 \%)$ & $9(69.2 \%)$ & $0(0 \%)$ \\
\hline Whole thickness & $0(0 \%)$ & $5(31.2 \%)$ & $0(0 \%)$ & $0(0 \%)$ \\
\hline
\end{tabular}

the findings by diagnosis. Genital CA also showed Ki67 positive cells besides the basal layer; in $54 \%$ of the cases the expression was observed in the whole thickness of the epithelium, while in $38 \%$ in focal superficial areas.

\section{Discussion}

Most oral papillary lesions share low-risk HPV subtypes (6/11), this raises the question whether these lesions belong to the same spectrum with different clinical presentation (3). We found HPV in $24 \%$ of 83 cases or benign hyperplastic epithelial oral lesions, similar to data reported in other studies about oral warts. Low risk subtypes were seen in $70 \%$ of the wide spectrum positive lesions, mostly cases of condyloma acuminatum.
Regarding to squamous papilloma, positivity for HPV is extremely variable in the literature (10-12), we found this association only in one case. Reported prevalence of high-risk HPV in oral samples are controversial, these subtypes are most commonly found in cervical and anogenital malignancies. In our study, they were not detected in any case, thus, indicating a possible mechanism of natural resistance of the oral epithelial cells to these aggressive subtypes. This is a possible explanation for the low association of oral cancer and HPV, different from the cervix and oropharynx (13-15). Cases positive for the wide-spectrum probe and negative for the specific probes, half of them with diagnosis of $\mathrm{VV}$ were in some way expected because these probes 
did not include the genotypes typically associated with this lesion: 2 and 57 (16). These cases may be probably positive for other subtypes included in the wide spectrum probe, such as $31,33,35,39,45,51$ or 52 , nevertheless these types are recognized as carcinogenic. None of the VV showed positivity for HPV 6/11, however, these types have been identified by ISH in $15 \%$ of oral VV as reported previously (10). Regarding the 2 cases of $\mathrm{MFEH}$, we expected negativity for all the probes used, because these lesions are known to be associated with HPV 13/32 (7), probes that are not commercially available. Nevertheless, one case affecting an 11-year-old boy was positive for the wide spectrum and 6/11 probes. As co-expression of genotypes has been observed, we could not rule out the presence of types 13 and 32, as we did not investigate with this probe.

Abundant koilocytes and an abnormal expression of Ki67 are features identified in most of the HPV associated lesions. In CA these viral altered cells were seen in the upper layers of epithelial crevices, as reported previously. Koilocytes have been identified in approximately $87 \%$ of oral condyloma and in a range from $27 \%$ to $45 \%$ of oral papilloma $(12,17)$. We found these cells in $93.7 \%$ of oral condyloma; and in $15.3 \%$ of squamous papilloma. In genital warts koilocytes are usually abundant and evident, while in oral mucosa these cells are more difficult to identify with certainty, because they can be confused with vacuolated epithelial cells, which are common in the oral epithelium. However, strict criteria for koilocyte identification should be applied; perinuclear clear halo, nuclear enlargement, hyperchromasia, irregular nuclear outlines, and multilobation should be identified (18).

Ki67 showed to be interesting to indicate association with HPV, as almost $70 \%$ of the cases showing a nonrestricted basal layer positivity, resulted to be HPV associated. It is important to consider that these lesions should be distinguished from epithelial dysplasias not associated with HPV.

One final point that deserves further consideration is that the squamous papillomas were mostly HPV negative. This is probably associated to the fact that from the more than 170 genotypes described, we used in this study only a limited number of probes, and it is unknown with certainty what percentage of the genome is common for those genotypes not commercially available. High discrepancies are found when using methods such as ISH or PCR, as the latter possess a higher sensitivity but lower specificity, and studies using PCR shows higher percentages of positivity (19). In conclusion, low-risk HPV 6/11 are the most common subtypes found in the oral cavity, even though, a small percentage of hyperplastic papillary lesions are associated with HPV, they comprise a wide group of lesions that deserves further studies to better clarify its classification and etiology.

\section{References}

1. Anderson KM, Perez-Montiel D, Miles L, Allen CM, Nuovo GJ. The histologic differentiation of oral condyloma acuminatum from its mimics. Oral Surg Oral Med Oral Pathol Oral Radiol Endod. 2003;96:420-8.

2. Tomson N, Sterling J, Ahmed I, Haque J, Berth-Jones J. Human papillomavirus typing of warts and response to cryotherapy. J Eur Acad Dermatol Venereol. 2011;25:1108-11.

3. Grce M, Mravak-Stipetić M. Human papillomavirus-associated diseases. Clin Dermatol. 2014;32:253-8.

4. Ljubojevic S, Skerlev M. HPV-associated diseases. Clin Dermatol. 2014;32:227-34.

5. Carlos R, Sedano HO. Multifocal papilloma virus epithelial hyperplasia. Oral Surg Oral Med Oral Pathol. 1994;77:631-5.

6. Durso BC, Pinto JM, Jorge J Jr, de Almeida OP. Extensive focal epithelial hyperplasia: case report. J Can Dent Assoc. 2005;71:76971.

7. Said AK, Leao JC, Fedele S, Porter SR. Focal epithelial hyperplasia - an update. J Oral Pathol Med. 2013;42:435-42.

8. Evans MF, Mount SL, Beatty BG, Cooper K. Biotinyl-tyramidebased in situ hybridization signal patterns distinguish human papillomavirus type and grade of cervical intraepithelial neoplasia. Mod Pathol. 2002;15:1339-47.

9. Fonseca FP, de Andrade BA, Rangel AL, Della Coletta R, Lopes MA, de Almeida OP et al. Tissue microarray is a reliable method for immunohistochemical analysis of pleomorphic adenoma. Oral Surg Oral Med Oral Pathol Oral Radiol. 2014;117:81-8.

10. Almeida Leite C, Rodrigues Acay R, Martim Reche P, da Silva OG, Machado de Sousa SO. Detection of human papillomavirus in oral warts using in situ hybridization. RGO. 2008;56:237-243.

11. Kansky AA, Seme K, Maver PJ, Luzar B, Gale N, Poljak N. Human papillomaviruses (HPV) in tissue specimens of oral squamous cell papillomas and normal oral mucosa. Anticancer Res. 2006;26:3197-201.

12. Eversole LR, Laipis PJ. Oral squamous papillomas: Detection of HPV DNA by in situ hybridization. Oral Surg Oral Med Oral Pathol. 1988;65:545-50.

13. Walline HM, Komarck C, McHugh JB, Byrd SA, Spector ME, Hauff SJ et al. High-risk human papillomavirus detection in oropharyngeal, nasopharyngeal, and oral cavity cancers: comparison of multiple methods. JAMA Otolaryngol Head Neck Surg. 2013;139:1320-7.

14. Herrero R, Castellsagué X, Pawlita M, Lissowska J, Kee F, Balaram P, et al. Human papillomavirus and oral cancer: the International Agency for Research on Cancer multicenter study. J Natl Cancer Inst. 2003;95:1772-83.

15. Forman D, de Martel C, Lacey CJ, Soerjomataram I, Lortet-Tieulent J, Bruni L, et al. Global burden of human papillomavirus and related diseases. Vaccine. 2012;30S:F12- F23.

16. Eversole LR, Laipis PJ, Green TL. Human papillomavirus type 2 DNA in oral and labial verruca vulgaris. J Cutan Pathol 1987:14:31925.

17. Eversole LR, Laipis PJ, Merrell P, Choi E. Demonstration of human papillomavirus DNA in oral condyloma acuminatum. J Oral Pathol. 1987;16:266-72.

18. Cho NH, Kang S, Hong S, Jeong GB, Choi IW, Choi HJ, et al. Multinucleation of koilocytes is in fact multilobation and is related to aberration of the G2 checkpoint. J Clin Pathol 2005;58:576-82.

19. Ribeiro MG, Marcolino LD, Ramos BR, Miranda EA, Trento CL, Jain S, et al. High prevalence of human papillomavirus (HPV) in oral mucosal lesions of patients at the Ambulatory of Oral Diagnosis of the Federal University of Sergipe, Northeastern Brazil. J Appl Oral Sci. 2017;25:69-74.

\section{Conflicts of interest}

The authors declare there are no conflicts of interest or disclosures regarding to this work. 